\title{
PROFESSIONAL DEVELOPMENT IN OPEN AND DISTANCE LEARNING SYSTEM: ANALYTICAL EVALUATION OF TRAINING PROGRAMMES
}

\author{
Anil K. Dimri (dimrianilk2002@yahoo.co.in) \\ Anil Kumar Misra \\ Indira Gandhi National Open University, India
}

\begin{abstract}
Present article seeks to analyze the impact of training programmes on the professional development skills of the academics working primarily at the Regional Centers of Indira Gandhi National Open University spread across the country. Article also seeks to analyze how the issues pertaining to the academics which include educational, administration, student support, supervision and maintenance of study centers. monitoring, staff development, survey and research activities, development of self instructional material, admission, examination, teleconferencing, interactive radio counseling, gyanvani, tele-learning center activities, maintenance of database, financial and administrative matters were taken up while imparting training. Interrelationship among the variables was also analyzed in order to asses the impact one variable on the other variables by using regression technique, i.e while dealing with the issues pertaining to educational administration the impact of training on monitoring was also assessed.
\end{abstract}

Key words: Open and Distance Learning System, professional development, training programmes evaluation

Open and Distance Learning (ODL) system in India has witnessed exceptional growth in terms of enrolment, mainly during the last two decades; consequently $24 \%$ learners among college entrants have chosen ODL system as their pursuit to higher education. It is quite likely that by the end of 2007, one third of population of college entrants would opt for ODL system to accomplish their higher educational needs. Indira Gandhi National Open University (IGNOU) in India is playing a major role to promote ODL system through its vast network of learner support centers (LSCs). It has developed an effective network of more than 1400 LSCs in the premier institutions of higher learning across the country. It advocates the philosophy of convergence which includes resource sharing between IGNOU and host institutions in terms of use of existing human and infrastructure resources of the host institutions and self instructional material and technology supported materials of IGNOU, which includes CD specially designed and developed for the distance learners, print material and use of communication technology including video conferencing, Gyandarshan, Gyanvani etc. Consequently the higher learning across the country becomes cost effective. As a result IGNOU has made significant dent in the field of ODL since its inception, as its philosophy suits both learner and host institutions. 
In order to manage such a vast network and deliver better support services to the learners, availability of sufficient skilled manpower is inevitable, particularly at the Regional Centers, spread across the country, where the learners have direct access and interaction with the functionaries, including academics involved in the delivery of programmes launched by the university. Besides academic support to the learners, their day to day administrative quarries which include pre admission counseling such as selection of programmes, rationale for selecting a particular programme, to ensure correct entries in the admission forms, how to pursue courses through ODL system. post admission counseling, preparation and timely submission of assignments, identification of supervisor and submission of project synopsis, management of teleconferencing, participation in interactive radio counseling and problems related to reflection of assignments grade, declaration of Term End result, change of address, change of elective and so on are also addressed efficiently and effectively resulting in direct interaction with the learners at the regional center. Realizing the importance of learner support services, IGNOU has created a cadre of academics who possesses similar qualification as the teachers posted at its headquarters to deal with the affairs of learners and to provide better support services to them which include academic and administrative support to the learners and administrative and financial management of learners support centers.

The academics posted at the Regional Centers across the country play pivotal role not only in the delivery of programmes developed by the university which include identification of host institution, visit to the host institution to assess feasibility in terms of academic and infrastructure facilities, monitoring of academic as well as administrative activities but also to ensure better support to the learners who are ultimate beneficiaries of ODL. Nevertheless IGNOU has organized training programmes to the academics in order to enhance their skill so that the desire objectives of the university could be achieved. It is in this context the present article seeks to analyze the impact of training programmes on the skill development of academics involved in the delivery and management of the academic programmes offered by the university. The need for training programme for the academics has been realized from time to time.

Pennell (1996) considers that with increasing participation rates in tertiary education, academic staff, who may have done their learning through face to face discussion or solitary burrowing through the stacks of the library will need to be trained to deliver and manage in the online learning environment. He goes to discuss and illustrate some specific software tools that are being developed to address this need. Staff training in $\mathrm{DE}$ is essential because for various reasons most of the faculty and non-teaching staff working in these institutions are drawn from conventional system. Most of them are not familiar with the DE system and its innovative methodologies, the openness, flexibility, student centered policies, use of self instructional materials and multimedia technologies, support services, continuous evaluation methods, etc. All of these can not be understood without proper training on these innovative practices (Muralimanohar, 1997).

The success of any distance education programme depends upon the implementation of the instructional system. Hence, training in admissions, course delivery, tutorial and guidance services, continuous and term end assessment is necessary for the academic and non- 
academic staff members, particularly those dealing with admissions, material distribution, computers and evaluation, and staff engaged in student support services at headquarters. Regional Centers and study centers (Mullick, 1997).

Staff training is an instrument to enhance the capabilities of the staff, and development is a process of advancement or progression in an organization by acquiring necessary knowledge, skills and attitudes. It is generally felt that a 'pre-service' training model might be more appropriate along with the Continuing Professional Development (CPD). Koul, (1990) also supports the pre-service training in distance education.

Panda and Bala (2004) points out that training must be seen in the form of continuing professional development and the CPD must contribute to continuing critical reflection and to individual development, besides institutional growth and development. Post Graduate Diploma in Distance Education (PGDDE) and Master of Arts in Distance Education (MADE) are the two programmes offered by IGNOU to train its academics and other academics working in the field of open and distance learning (ODL). Another model of staff and professional development, adopted by IGNOU is the thematic round tables conducted by State Open Universities at the Regional level.

Except for the long-term professional development programmes (PGDDE \& MADE), face to face is the predominant method of training with occasional use of teleconferencing. It is well recognized that teachers/ academics have multiple roles to perform which include teaching, research, development of learning resource material, extension and managing the institution for which integrated and coordinated programmes for professional development are considered necessary (Yadav \& Panda, 1997). No profession can grow unless its members are prepared to grow professionally and are even prepared to undergo scarifies in order to do so. It is being increasingly realized that distance education is a highly specialized task and thus those teachers/ academics who are induced into it need to be given pre-entry training and in-service refresher courses, summer schools and periodic seminars (Bhatnagar, 1997).

Ramanujam (1995) stressing on the importance of training for distance education academics stated that the growing awareness and realization of the need for systematic and comprehensive training programmes for all those who are involved in the practice of distance education, have made it possible to have general staff training programmes in Distance Education.

Therefore the main objective of this article is to make a critical analysis of the on going training programmes and their impact on the academics for whom the training programmes are developed. Nevertheless the article also seeks to analyze the interrelationship among the different variables addressed in the training programmes. For instance, while addressing one variable the change taking place in another variable is also analyzed. Therefore the article mainly focuses to evaluate the effectiveness of existing training programmes and to what extent these programmes were able to address the training needs of the academics. 


\section{METHODOLOGY}

In the present research a questionnaire was developed for academics working at IGNOU headquarters and its Regional Centers across the country for collection of primary data on wide range of issues pertaining to type of training, duration, content, style, usefulness, adequacy, methodology and number of training programmes attended and to what extent these training programmes were relevant and useful in day to day issues pertaining to academics such as educational administration, student support, supervision and maintenance of study centers, monitoring, staff development, survey and research activities, development of self instructional material, admission, examination, teleconferencing, interactive radio counseling, gyanvani, tele-learning center activities, maintenance of database, financial and administrative matters. Secondary data was collected from various published sources.

Method of stratified sampling technique has been applied. The sample for the research study was selected from among the academics. Therefore, the questionnaire was dispatched to the academics through post, email and more than 60 academics were personally contacted. As a result 32 academics who have responded the questionnaire in writing were covered in the sample, which accounts for $29.10 \%$ of the total academics working in the University. Out of 32 academics, 25 have obtained formal Post Graduate Diploma in Distance Education offered by IGNOU. Similarly among the surveyed academics, 22 were male and remaining female. On the other hand, 12 were middle level and remaining junior level academics. So far as experience and length of service of the academics is concerned, $50 \%$ academics were having experience of 5-10 years followed by $18.75 \%$ academics having experience more than 15 years. Relatively higher proportion of academics having experience 5-10 years responded questionnaire.

Data was classified in cross tables and multivariate tables, mathematical and statistical tools such as correlation, regression, kurtosis, and skewness were applied to draw the conclusion.

Kurtosis was calculated from the following equation:

$$
\left\{\frac{n(n+1)}{(n-1)(n-2)(n-3)} \sum\left(\frac{x_{i}-\bar{x}}{s}\right)^{4}\right\}-\frac{3(n-1)^{2}}{(n-2)(n-3)}
$$

In which $s$ is the sample standard deviation.

Kurtosis refers to the degree of flatness or peakedness in the region about the mode of a frequency curve. The degree of kurtosis of a distribution is measured relative to the peakedness of a normal curve. If a curve is more peaked than the normal curve it is called 'leptokurtic', if it is more flat-topped than the normal curve it is called 'platykurtic' or flat-topped. The normal curve itself is known as 'mesokurtic'. 
Skewness was calculated by using following equation:

$$
\frac{n}{(n-1)(n-2)} \sum\left(\frac{x_{i}-\bar{x}}{s}\right)^{3}
$$

In a positively skewed distribution mean is greater than the mode and the median lies somewhere in-between mean and mode. A positively skewed distribution contains some values that are much larger than the majority of other observations. In a negatively skewed distribution mode is greater than the mean and the median lies in-between mean and mode. The mean is pulled towards the low-valued item (that is, to the left). A negatively skewed distribution contains some values that are much smaller than the majority of observations.

Correlation coefficient can be calculated from the following equation:

$$
\rho_{x, y}=\frac{\operatorname{Cov}(X, Y)}{\sigma_{x} \cdot \sigma_{y}}
$$

where $-1 \leq \rho_{x, y} \leq 1$

and $\operatorname{Cov}(X, Y)=\frac{1}{n} \sum_{i=1}^{n}\left(x_{i}-\mu_{x}\right)\left(y_{i}-\mu_{y}\right)$

The value of the coefficient of correlation as obtained by the above formula shall always lie between \pm 1 . When $\rho_{x, y}=+1$, it means there is prefect positive correlation between the variables. When $\rho_{x, y}=-1$, it means there is perfect negative correlation between the variables. When, it mean $\rho_{x, y}=0 \mathrm{~s}$ there is no relationship between the two variables. However, in practice, such values of $\rho_{x, y}$ as $+1,-1$, and 0 are rare. We normally get values which lie between +1 and -1 such as $0.8,0.4$, etc. The coefficient of correlation describes not only the magnitude of correlation but also its direction. Thus, +0.8 would mean that correlation is positive because the sign of $\rho_{x, y}$ is + and the magnitude of correlation is 0.8 .

Regression equation between $\mathrm{x}$ and $\mathrm{y}$ can be expressed as $y=a x+b$

Where $b=$ constant and $a=$ coefficient of $x$

In this equation $a$ and $b$ are two unknown constants (fixed numerical values) which determine the position of the line completely. These constants are called the parameters of the line. If the value of either or both of them is changed, another line is determined. The parameter ' $b$ ' determines the level of the fitted line (i.e., the distance of the line directly above or below the origin). The parameter 'a' determines the slope of the line, i.e., the change in $y$ for unit change in $\mathrm{x}$. 


\section{RESULT AND DISCUSSION}

IGNOU organizes training programmes to its functionaries on a wide range of themes which includes use of ITC in ODL system, orientation programmes on counseling, for newly recruited professionals and short term programmes on administrative, academic and finance related issues, etc. The analysis of the number of training programme attended by the academics reveals that $25 \%$ academics have not attended any training programme at all. On the other hand $15.62 \%$ have attended only one programme and $18.75 \%$ have attended two programmes. It is also evident that $6.25 \%$ academics have attended more than 4 training programmes. Looking at the duration of the training programmes it was reported that $58.34 \%$ training programmes were of short duration of 1-3 days. Only $9.52 \%$ training programme 41.18 were of 8-14 days. Nevertheless majority of training programmes $(41.18 \%$ ) were on work specific topics followed by use of computer and information technology ( $24.11 \%)$. Orientation programmes were also organized mainly for the new recruits. It is surprising to note that for most of the training programmes mode of the training was face to face only and no attempt was made to use teleconferencing for training the professionals. However in the recent time more focus on use of tele-conferencing is being given. It is evident to note that $59.30 \%$ participants have reported that they were satisfied with the training programmes.

The academics have rated various issues pertaining to quality of training on parameter $A$ to 0 on five point scale. As evident from the Table 1,70\% academics have rated that content of the training programmes very good followed by $34.12 \%$ good. On the other hand, $51.77 \%$ academics have rated that the density of the programme was good. Similarly $50.59 \%$ have reported that the style of the training programme was also good. On the other hand the rating for language, practical aspects and adequacy of the training programme, $56.14,81.18$, and $84.71 \%$ respectively as very good. It may be noted that majority of the academics have indicated that language, practical aspects and adequacy of the training programme was very good and good on five point scale, which reflects that the training imparted by the university has adequately addressed the professional needs of the participants.

In our earlier article (Dimri \& Misra, 2006), in depth analysis of parameters such as educational administration (A) and monitoring (D) has been carried out. Statistical tools were applied to analyze the result of two variables $A$ and $D$ in order to assess whether a relationship could be established between educational administrations and monitoring, as monitoring of various activities by the academics placed across the country is very important and crucial for the effective management of DE programmes in IGNOU. It is pertinent to note that Table 1 has also indicated that the responses of the academics are satisfactorily represented across the variables. Consequently, in the present analysis an attempt has been made to assess the relationship of all the variables with each other making the analysis more in-depth. 
Table 1. Response of Academics on Qualitative Aspect

\begin{tabular}{|l|c|c|c|c|c|}
\hline $\begin{array}{c}\downarrow \\
\text { Qualitative }\end{array}$ & Grading \\
\hline Content & Excellent \% & V.Good \% & Good \% & Average \% & Poor \\
\hline Descity & 14.12 & 44.70 & 34.12 & 7.06 & 0 \\
\hline Style & 2.35 & 38.82 & 51.77 & 7.06 & 0 \\
\hline Language & 15.29 & 31.77 & 50.59 & 2.35 & 0 \\
\hline Practical Aspects & 2.38 & 56.14 & 36.91 & 3.57 & 0 \\
\hline Adequacy & 12.94 & 81.18 & 5.88 & - & 0 \\
\hline
\end{tabular}

In Table 2, while analyzing the result of skewness with respect to educational administration (A) and other variables as given in Table 2, it may be noted that the result of skewness were computed 0.08 for student support, 0.73 for supervision and maintenance of study centers, 0.93 for monitoring and 0.30 for staff development. The trend of the result was similar for the other variables that clearly indicate that improvement is needed in the quality of training in order to satisfy the professional needs of the academics. Nevertheless, in general the participants were satisfied with the training programme imparted for their skill development. On the other hand result of correlation were also positive in most of the cases, and it was computed highly positive for educational administration and examination (0.99), maintenance of data base (0.94), financial and administrative matters (0.94), teleconferencing (0.81) and interactive radio counseling (0.81). However, the correlation for development of self instructional material $(-0.06)$ and gyanvani $(-0.66)$ was negative which indicates that less focus on these issues were given while addressing the educational administration. It can be concluded that the positive relationship with the number of variables reflects that these issues were addressed in better manner while addressing the educational administration.

While applying the regression analysis with respect to educational administration $(A)$ and student support (B), supervision and maintenance study center $(C)$, monitoring $(D)$, staff development $(E)$, survey $(F)$, admission $(H)$, interactive radio counseling $(K)$ and gyanvani $(L)$, we can interpret that $B, C, D, E, F, H, K$ and $L$ etc. are monitored with respect to $A$ the evaluated error (R squared) of $0.35,0.40,0.20,0.23,0.43,0.04$ and 0.43 respectively for educational administration with 3 changing values depending upon the existence of trainees/ training indicates that the monitoring is perfect and training imparted on these variables was up to the mark. However, while addressing the issues pertaining to teleconferencing $(\mathrm{J})$ the evaluated error was 0.66 , which is also tolerable. The training for examination (0.97), maintenance of database (0.89) and financial and administrative matters $(0.88)$ was not good as evaluated error on these parameters was considerably high, which indicates that more focus was required while addressing these issues. 
Table 2. Relationship of Educational Administration with other Variables

\begin{tabular}{|c|c|c|c|c|c|c|c|c|c|c|}
\hline \multirow[b]{2}{*}{ 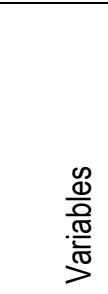 } & \multirow[b]{2}{*}{ 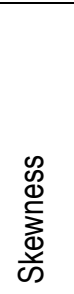 } & \multirow[b]{2}{*}{ 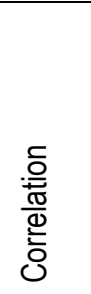 } & \multirow[b]{2}{*}{ 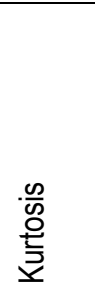 } & \multicolumn{7}{|c|}{ Regression } \\
\hline & & & & 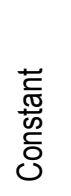 & 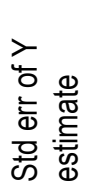 & 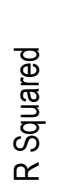 & 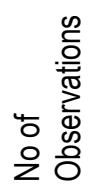 & 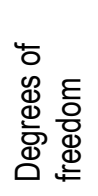 & 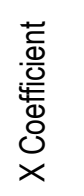 & 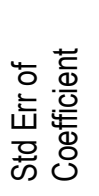 \\
\hline$A$ to $B$ & 0.08 & 0.59 & -0.74 & 1.53 & 1.97 & 0.35 & 5 & 3 & 0.53 & 0.41 \\
\hline A to $C$ & 0.73 & 0.21 & 0.47 & 1.75 & 1.13 & 0.04 & 5 & 3 & 0.09 & 0.24 \\
\hline A to $D$ & 0.93 & 0.44 & -0.20 & 1.30 & 2.60 & 0.20 & 5 & 3 & 0.46 & 0.54 \\
\hline A to $E$ & 0.30 & 0.48 & -0.88 & 1.67 & 1.70 & 0.23 & 5 & 3 & 0.33 & 0.36 \\
\hline A to $F$ & 0.24 & 0.50 & -1.10 & 1.47 & 2.29 & 0.25 & 5 & 3 & 0.47 & 0.48 \\
\hline A to $G$ & 0.24 & -0.06 & -0.26 & 2.30 & 1.71 & 0.00 & 5 & 3 & -0.04 & 0.36 \\
\hline A to $\mathrm{H}$ & 0.44 & 0.66 & -0.52 & 1.63 & 2.01 & 0.43 & 5 & 3 & 0.63 & 0.42 \\
\hline A to I & 0.25 & 0.99 & -1.20 & 0.54 & 0.39 & 0.97 & 5 & 3 & 0.88 & 0.08 \\
\hline A to $\mathrm{J}$ & 0.07 & 0.81 & -1.40 & 0.74 & 1.46 & 0.66 & 5 & 3 & 0.74 & 0.31 \\
\hline A to $K$ & 0.48 & 0.81 & -1.11 & 2.49 & 2.26 & 0.04 & 5 & 3 & -0.18 & 0.47 \\
\hline A to $L$ & 0.82 & -0.66 & -0.16 & 2.81 & 1.13 & 0.43 & 5 & 3 & -0.36 & 0.24 \\
\hline A to $M$ & 0.67 & 0.08 & 0.64 & 1.70 & 1.26 & 0.01 & 5 & 3 & 0.04 & 0.26 \\
\hline A to $\mathrm{N}$ & 0.07 & 0.94 & -1.51 & 0.79 & 0.77 & 0.89 & 5 & 3 & 0.79 & 0.16 \\
\hline A to 0 & 0.05 & 0.94 & -1.31 & 0.32 & 0.82 & 0.88 & 5 & 3 & 0.82 & 0.17 \\
\hline
\end{tabular}

$A=$ Educational Administration, $6=$ Student Support, $C=$ Supervision and Maintenance of Study Centers, $D=$ Monitoring, $E=S$ taff Development, $F=$ Survey and Research Activities, $G=$ Development of Self Instructional Material, $\mathrm{H}=$ Admission, I=Examination, $\mathrm{J}=$ Teleconferencing, $\mathrm{K}=$ Interactive Radio Counseling, L=Gyanvani, $\mathrm{M}=$ Tele - Learning Center Activities, $\mathrm{N}=$ Maintenance of database, and $\mathrm{O}=$ Financial \& Administrative Matters

In order to make analysis more meaningful, attempt has also been made to analyze the interrelationship among the student support and other variables included in the analysis. The result of skewness indicates that trainers could not address the issues of teleconferencing ($0.03)$ and financial and administrative matters $(-0.08)$ adequately with relation to student support. The result on other variables also indicates that improvement is needed in the training. The correlation values are also not encouraging as it has been computed negative for number of variables except supervision and maintenance of study centers (0.71), monitoring $(0.85)$, admission (0.77), examination (0.50), interactive radio counseling (0.35), teleconferencing (0.49). On the other hand the result of kurtosis for support maintenance of database (0.71), financial and administrative matters $(0.51)$, services and supervision and maintenance of study center were $(-0.09)$, survey and research $(-0.50)$, examination $(-0.57)$, teleconferencing $(-0.78)$, maintenance of database $(-0.88)$, financial and administrative matters $(-0.66)$ were computed negative which indicates that improvement is needed in quality of the training. 
Table 3. Relationship of Student Support with other Variables

\begin{tabular}{|c|c|c|c|c|c|c|c|c|c|c|}
\hline \multirow[b]{2}{*}{$\begin{array}{l}\frac{\mathscr{d}}{0} \\
\frac{\pi}{0} \\
\frac{0}{\omega} \\
\frac{0}{\pi}\end{array}$} & \multirow[b]{2}{*}{ 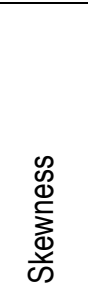 } & \multirow[b]{2}{*}{$\begin{array}{l}\text { 음 } \\
\frac{0}{0} \\
\frac{\pi}{0} \\
\frac{0}{0} \\
0\end{array}$} & \multirow[b]{2}{*}{ 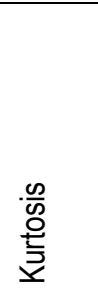 } & \multicolumn{7}{|c|}{ Regression } \\
\hline & & & & 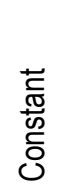 & 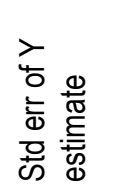 & 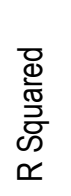 & 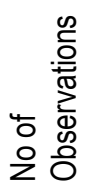 & 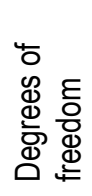 & 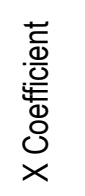 & 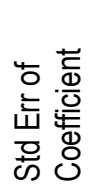 \\
\hline$B \& C$ & 0.65 & 0.71 & 1.54 & 1.00 & 0.82 & 0.50 & 5 & 3 & 0.33 & 0.19 \\
\hline$B \& D$ & 0.94 & 0.85 & 0.30 & -0.40 & 1.55 & 0.71 & 5 & 3 & 1.00 & 0.37 \\
\hline$B \& E$ & 0.23 & -0.42 & -0.09 & 3.60 & 1.75 & 0.18 & 5 & 3 & -0.33 & 0.41 \\
\hline$B \& F$ & 0.17 & -0.31 & -0.50 & 3.80 & 2.50 & 0.10 & 5 & 3 & -0.33 & 0.59 \\
\hline$B \& G$ & 0.17 & -0.24 & 0.69 & 2.70 & 1.66 & 0.06 & 5 & 3 & -0.17 & 0.39 \\
\hline$B \& H$ & 0.48 & 0.77 & 0.18 & 0.90 & 1.70 & 0.59 & 5 & 3 & 0.83 & 0.40 \\
\hline B \& I & 0.21 & 0.50 & -0.57 & 1.50 & 2.12 & 0.25 & 5 & 3 & 0.50 & 0.50 \\
\hline B \& J & -0.03 & 0.49 & -0.78 & 1.30 & 2.18 & 0.24 & 5 & 3 & 0.50 & 0.51 \\
\hline$B \& K$ & 0.36 & 0.35 & -0.66 & 1.00 & 2.16 & 0.13 & 5 & 3 & 0.33 & 0.51 \\
\hline$B \& L$ & 0.73 & -0.81 & 0.47 & 3.30 & 0.88 & 0.66 & 5 & 3 & -0.50 & 0.21 \\
\hline$B \& M$ & 0.54 & -0.32 & 1.62 & 2.30 & 1.20 & 0.10 & 5 & 3 & -0.17 & 0.28 \\
\hline$B \& N$ & 0.00 & 0.71 & -0.88 & 1.00 & 1.63 & 0.50 & 5 & 3 & 0.67 & 0.38 \\
\hline B \& O & -0.08 & 0.51 & -0.66 & 1.10 & 2.06 & 0.26 & 5 & 3 & 0.50 & 0.48 \\
\hline
\end{tabular}

$A=$ Educational Administration, $8=$ Student Support, $C=$ Supervision and Maintenance of Study Centers, $\mathrm{D}=$ Monitoring, $\mathrm{E}=$ Staff Development, $\mathrm{F}=$ Survey and Research Activities, $\mathrm{G}=$ Development of Self Instructional Material, $\mathrm{H}=$ Admission, I=Examination, J=Teleconferencing, $\mathrm{K}=$ Interactive Radio Counseling, L=Gyanvani, $\mathrm{M}=$ Tele - Learning Center Activities, $\mathrm{N}=$ Maintenance of database, and $\mathrm{O}=$ Financial \& Administrative Matters.

The result of regression analysis with respect to student support (B) and other variables such as supervision and maintenance of study centers, monitoring, staff development, survey and research activities, development of self instructional material, admission, examination, teleconferencing, interactive radio counseling, gyanvani, telelearning center activities, maintenance of database and financial and administrative matters with evaluated error $(R$ squared) of less than 0.70 indicates that training imparted to the participants was useful except monitoring (0.71) and gyanvani (0.66). Training to address the issues of gyanvani was also tolerable; however, it was not at all satisfactory for monitoring. It may be noted that monitoring is an important activity to be performed by the academics at the Regional Centers.

From the Table 4 it is evident to note that value of skewness are negative for development of self instructional material $(-0.23)$, and tele-learning center activities $(-(-0.61)$, indicating that the trainers could not address these issues satisfactorily. The negative values of correlation for staff development, survey and research activities, development of self instructional material, gyanvani and interactive radio counseling indicates that supervision and maintenance of study centers and these variables are negatively correlated. The result of kurtosis for development of self instructional material $(-037)$, teleconferencing $(-0.40)$, gyanvani $(-0.52)$, tele - learning center activities $(-0.16)$, maintenance of database $(-0.90)$, and financial \& administrative matters $(-0.76)$ shows that improvement is needed in the training programmes. 
Table 4. Relationship of Supervision and Maintenance of Study Centers with other Variables

\begin{tabular}{|c|c|c|c|c|c|c|c|c|c|c|}
\hline \multirow[b]{2}{*}{ 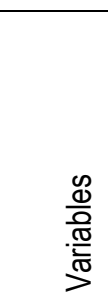 } & \multirow[b]{2}{*}{ 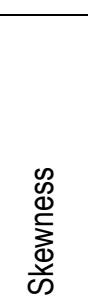 } & \multirow[b]{2}{*}{$\begin{array}{l}\text {.0 } \\
\frac{0}{0} \\
\frac{0}{0} \\
0 \\
0\end{array}$} & \multirow[b]{2}{*}{$\begin{array}{l}\frac{\infty}{\omega 0} \\
\frac{0}{5} \\
\frac{1}{2}\end{array}$} & \multicolumn{7}{|c|}{ Regression } \\
\hline & & & & 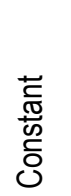 & 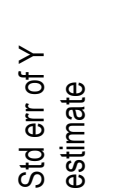 & 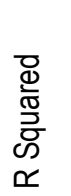 & 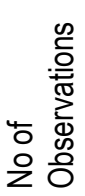 & 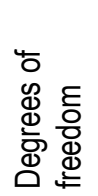 & 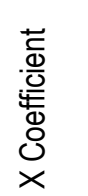 & 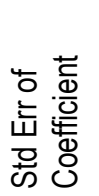 \\
\hline$C \& D$ & 2.17 & 0.50 & 5.42 & 0.10 & 2.51 & 0.25 & 5 & 3 & 1.25 & 1.26 \\
\hline$C \& E$ & 0.71 & -0.60 & 0.13 & 4.60 & 1.55 & 0.36 & 5 & 3 & -1.00 & 0.77 \\
\hline$C \& F$ & 0.88 & -0.44 & 1.13 & 4.80 & 2.37 & 0.19 & 5 & 3 & -1.00 & 1.18 \\
\hline$C \& G$ & -0.23 & -0.51 & -0.37 & 3.70 & 1.48 & 0.26 & 5 & 3 & -0.75 & 0.74 \\
\hline $\mathrm{C} \& \mathrm{H}$ & 1.51 & 0.33 & 2.89 & 1.90 & 2.51 & 0.11 & 5 & 3 & 0.75 & 1.26 \\
\hline$C \& 1$ & 1.02 & 0.12 & 0.83 & 2.50 & 2.43 & 0.01 & 5 & 3 & 0.25 & 1.22 \\
\hline C\&J & 0.50 & 0.12 & -0.40 & 2.30 & 2.49 & 0.01 & 5 & 3 & 0.25 & 1.24 \\
\hline$C \& K$ & 0.75 & 0.25 & 0.26 & 1.00 & 2.24 & 0.06 & 5 & 3 & 0.50 & 1.12 \\
\hline$C \& L$ & 0.86 & -0.77 & -0.52 & 3.80 & 0.97 & 0.59 & 5 & 3 & -1.00 & 0.48 \\
\hline$C \& M$ & -0.61 & 0.69 & -0.16 & 3.30 & 0.92 & 0.47 & 5 & 3 & -0.75 & 0.46 \\
\hline$C \& N$ & 0.63 & 0.25 & -0.90 & 2.00 & 2.24 & 0.06 & 5 & 3 & 0.50 & 1.12 \\
\hline C\&O & 0.25 & 0.00 & -0.76 & 2.60 & 2.39 & 0.00 & 5 & 3 & 0.00 & 1.20 \\
\hline
\end{tabular}

$A=$ Educational Administration, $B=$ Student Support, $C=$ Supervision and Maintenance of Study Centers, $\mathrm{D}=$ Monitoring, $\mathrm{E}=$ Staff Development, '=Survey and Research Activities, $\mathrm{G}=$ Development of Self Instructional Material, $\mathrm{H}=$ =Admission, I=Examination, ]=Teleconferencing, K=Interactive Radio Counseling, L=Gyanvani, $\mathrm{M}=$ Tele - learning Center Activities, $\mathrm{N}=$ Maintenance of database, and $\mathrm{O}=$ Financial \& Administrative Matters.

The result of regression analysis with respect to supervision and maintenance of study centers (C) and other variables such as monitoring, staff development, survey and research activities, development of self instructional material, admission, examination, teleconferencing, interactive radio counseling, gyanvani, tele - learning center activities, maintenance of database, and financial \& administrative matters with evaluated error ( $R$ squared) of less than 0.60 indicates that training imparted to the participants was useful in addressing these issues.

From the Table 5, it is evident to note that the result of skewness for monitoring and other variables were positive which indicates that the training was up to the mark. On the other hand negative correlation for staff development (-0.41), survey and research activities (-11) and gyanvani (-0.41) indicates that the training was not satisfactory while addressing these issues with respect to monitoring. It may also be noted that highly positive correlation ( 0.94$)$ has been noted for admission which indicates that the relationship between the monitoring and admission was perfectly correlated. 
Table 5. Relationship of Monitoring with other Variables

\begin{tabular}{|c|c|c|c|c|c|c|c|c|c|c|}
\hline \multirow[b]{2}{*}{ 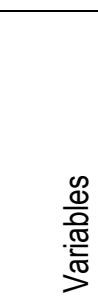 } & \multirow[b]{2}{*}{ 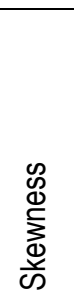 } & \multirow[b]{2}{*}{ 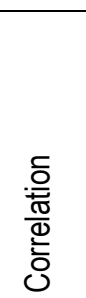 } & \multirow[b]{2}{*}{$\begin{array}{l}\frac{\infty}{\omega 0} \\
\frac{0}{5} \\
\frac{1}{2}\end{array}$} & \multicolumn{7}{|c|}{ Regression } \\
\hline & & & & 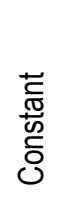 & 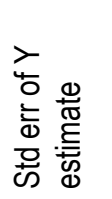 & 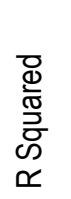 & 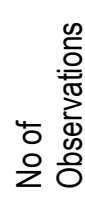 & 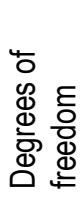 & 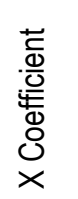 & 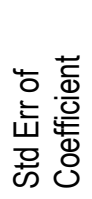 \\
\hline$D \& E$ & 1.41 & -0.41 & 1.46 & 3.30 & 1.77 & 0.16 & 5 & 3 & -0.27 & 0.35 \\
\hline$D \& F$ & 1.04 & -0.11 & 0.10 & 3.05 & 2.62 & 0.01 & 5 & 3 & -0.10 & 0.52 \\
\hline$D \& G$ & 1.53 & 0.30 & 3.06 & 1.75 & 1.64 & 0.09 & 5 & 3 & 0.17 & 0.33 \\
\hline $\mathrm{D \& H}$ & 1.15 & 0.94 & -0.01 & 1.15 & 0.88 & 0.89 & 5 & 3 & 0.87 & 0.18 \\
\hline$D \& 1$ & 1.10 & 0.42 & -0.05 & 2.07 & 2.22 & 0.18 & 5 & 3 & 0.36 & 0.44 \\
\hline D\&J & 0.93 & 0.67 & -0.08 & 1.29 & 1.86 & 0.45 & 5 & 3 & 0.58 & 0.37 \\
\hline$D \& K$ & 1.41 & 0.75 & 1.45 & 0.45 & 1.54 & 0.56 & 5 & 3 & 0.60 & 0.31 \\
\hline$D \& L$ & 2.07 & -0.41 & 4.30 & 2.36 & 1.37 & 0.17 & 5 & 3 & -0.21 & 0.27 \\
\hline$D \& M$ & 2.05 & 0.15 & 5.55 & 1.63 & 1.25 & 0.02 & 5 & 3 & 0.06 & 0.25 \\
\hline$D \& N$ & 0.99 & 0.70 & -0.25 & 1.56 & 1.66 & 0.49 & 5 & 3 & 0.56 & 0.33 \\
\hline$D \& O$ & 0.97 & 0.30 & 0.36 & 1.96 & 2.29 & 0.09 & 5 & 3 & 0.25 & 0.46 \\
\hline
\end{tabular}

$D=$ Monitoring, $E=$ Staff Development, $F=$ Survey and Research Activities, $G=$ Development of Self Instructional Material, $\mathrm{H}=$ Admission, I=Examination, J=Teleconferencing, $\mathrm{K}=$ Interactive Radio Counseling, $\mathrm{L}=$ Gyanvani, $\mathrm{M}=$ Tele - Learning Center Activities, $\mathrm{N}=$ Maintenance of database, and $\mathrm{O}=$ Financial \& Administrative Matters

Though the results of kurtosis are positive for most of the variables which indicates that the training imparted to the participants was up to the mark. However the negative results for admission (-0.01), examination $(-0.05)$, teleconferencing $(-0.08)$ and maintenance of data base $(-0.25)$ has clearly indicated that improvement is needed in the quality of training to address these issues particularly with respect to monitoring.

While analyzing the result of regression with respect to monitoring and other variables it is revealed that for a number of variables value of evaluated error (R squared) was computed less than $60 \%$ which indicates that the training was perfect on these variables.

Monitoring and staff development are the two major activities performed by the academic staff posted at the regional centers across the country. The important function for staff development includes appointment of part time functionaries at the study centers, conducting and imparting orientation programmes for academic counselors as most of them are mainly working in the conventional system and have a very little or no knowledge about the functioning of ODL system. The academic counselors engaged for academic counseling at the study centers are also trained in the field of ODL system. Therefore the result of staff development have been analyzed with respect to survey and research activities, development of self instructional material, admission, examination, teleconferencing, interactive radio counseling, gyanvani, tele - learning center activities, maintenance of database and financial \& administrative matters. Table 6. Relationship of Staff Development with other Variables 


\begin{tabular}{|c|c|c|c|c|c|c|c|c|c|c|}
\hline \multirow[b]{2}{*}{$\begin{array}{l}\frac{\mathscr{0}}{\frac{\pi}{\pi}} \\
\frac{\pi}{\pi} \\
\frac{\pi}{\pi}\end{array}$} & \multirow[b]{2}{*}{ 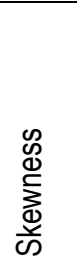 } & \multirow[b]{2}{*}{ 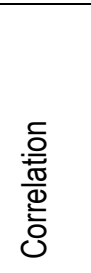 } & \multirow[b]{2}{*}{ 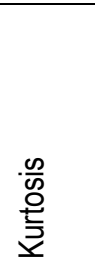 } & \multicolumn{7}{|c|}{ Regression } \\
\hline & & & & 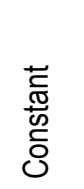 & 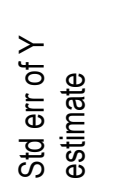 & 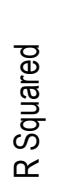 & 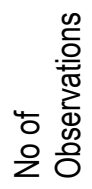 & 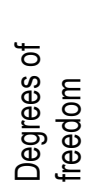 & 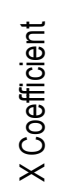 & 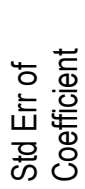 \\
\hline$E \& F$ & 0.42 & 0.89 & -0.57 & -0.36 & 1.20 & 0.79 & 5 & 3 & 1.21 & 0.36 \\
\hline$E \& G$ & 0.12 & 0.24 & -0.37 & 1.64 & 1.66 & 0.06 & 5 & 3 & 0.21 & 0.50 \\
\hline$E \& H$ & 0.91 & -0.08 & 0.59 & 3.68 & 2.65 & 0.01 & 5 & 3 & -0.11 & 0.79 \\
\hline$E \& I$ & 0.51 & 0.56 & -0.86 & 1.14 & 2.02 & 0.32 & 5 & 3 & 0.71 & 0.60 \\
\hline$E \& J$ & 0.14 & 0.39 & -1.33 & 1.50 & 2.31 & 0.15 & 5 & 3 & 0.50 & 0.69 \\
\hline$E \& K$ & 0.49 & -0.60 & -1.06 & 3.86 & 1.85 & 0.36 & 5 & 3 & -0.71 & 0.55 \\
\hline$E \& L$ & 0.87 & 0.18 & -0.51 & 1.43 & 1.48 & 0.03 & 5 & 3 & 0.14 & 0.44 \\
\hline$E \& M$ & 0.48 & 0.49 & 0.81 & 0.96 & 1.10 & 0.24 & 5 & 3 & 0.32 & 0.33 \\
\hline$E \& N$ & 0.22 & 0.30 & -1.73 & 2.07 & 2.20 & 0.09 & 5 & 3 & 0.36 & 0.66 \\
\hline$E \& O$ & 0.97 & 0.52 & -1.37 & 0.93 & 2.05 & 0.27 & 5 & 3 & 0.64 & 0.61 \\
\hline
\end{tabular}

$E=S t a f f$ Development, $F=$ Survey and Research Activities, G=Development of Self Instructional Material, $\mathrm{H}=$ Admission, I=Examination, $\mathrm{J}=$ Teleconferencing, $\mathrm{K}=$ Interactive Radio Counselling, $\mathrm{L}=$ Gyanvani, $\mathrm{M}=$ Tele - Learning Center Activities, $\mathrm{N}=$ Maintenance of database, and $\mathrm{O}=\mathrm{Financial}$ \& Administrative Matters

It is interesting to note that the result of skewness are positive for all the variables (Table 6) which indicates that the training could address the issues with respect to staff development, adequately though some improvement is needed in the quality of training. The result of correlation has also been computed positive for majority of the variables which indicates that training on these variables was perfect. However negative result of correlation for admission ($0.08)$ and interactive radio counseling $(-0.60)$ shows that these issues could not be addressed perfectly.

The result of kurtosis were computed negative for majority of variables except admission, (0.59) and maintenance of data base (0.81) indicating that improvement is needed in the quality of training. While looking at the result of the regression it is interesting to note that evaluated error ( $R$ Squared) for survey and research was 0.79 which indicates that training was not tolerable with respect to survey and research. Nevertheless the training on other issues was perfectly suiting to the requirement of the participants.

Admission is another important activity to be performed by the academics at the regional centers; therefore the relationship of admission with other variables is very crucial and important. As evident from the table-7 the result of skewness are positive for all the variables which indicates that the training was relatively good, however improvement is needed to address these issues. The results of correlation are also positive reflecting that the training with respect to admission and examination (0.67), teleconferencing $(0.87)$, interactive radio counseling (0.59), gyanvani 0.67), tele - learning center activities(0.34), maintenance of database (0.87), and financial \& administrative matters (0.51) are all positive reflecting that the training on admission with respects to these variables was highly correlated. On the other hand the result of kurtosis for examination $(-0.47)$, teleconferencing $(-0.38)$, maintenance of 
database $(-0.56)$, and financial \& administrative matters $(-0.05)$, indicates that improvement is needed in the quality of training.

Table 7. Relationship of Admission with other Variables

\begin{tabular}{|c|c|c|c|c|c|c|c|c|c|c|}
\hline \multirow[b]{2}{*}{$\begin{array}{l}\mathscr{0} \\
\frac{\mathbb{1}}{0} \\
\frac{\pi}{\pi} \\
\frac{\pi}{\pi}\end{array}$} & \multirow[b]{2}{*}{ 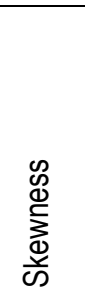 } & \multirow[b]{2}{*}{ 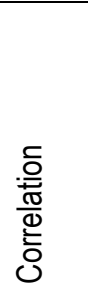 } & \multirow[b]{2}{*}{$\begin{array}{l}\frac{0}{00} \\
\frac{0}{5} \\
\frac{1}{2}\end{array}$} & \multicolumn{7}{|c|}{ Regression } \\
\hline & & & & 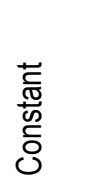 & 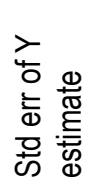 & 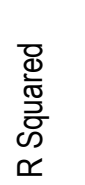 & 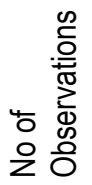 & 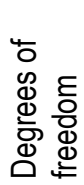 & 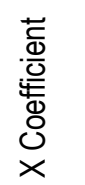 & 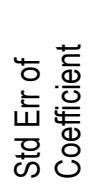 \\
\hline $\mathrm{H} \& \mathrm{I}$ & 0.66 & 0.67 & -0.47 & 0.92 & 1.83 & 0.44 & 5 & 3 & 0.61 & 0.40 \\
\hline $\mathrm{H} \& \mathrm{~J}$ & 0.07 & 0.87 & -0.38 & 0.01 & 1.23 & 0.76 & 5 & 3 & 0.82 & 0.27 \\
\hline$H \& K$ & 0.81 & 0.59 & 0.16 & 0.24 & 1.85 & 0.36 & 5 & 3 & 0.52 & 0.40 \\
\hline$H \& L$ & 1.37 & 0.67 & 1.77 & 2.54 & 1.39 & 0.15 & 5 & 3 & -0.22 & 0.30 \\
\hline$H \& M$ & 1.33 & 0.34 & 2.93 & 1.25 & 1.19 & 0.11 & 5 & 3 & 0.16 & 0.26 \\
\hline$H \& N$ & 0.54 & 0.87 & -0.56 & 0.43 & 1.14 & 0.75 & 5 & 3 & 0.75 & 0.25 \\
\hline $\mathrm{H} \& \mathrm{O}$ & 0.44 & 0.51 & -0.05 & 1.03 & 2.06 & 0.26 & 5 & 3 & 0.46 & 0.45 \\
\hline
\end{tabular}

$\mathrm{H}=$ Admission, I=Examination, J=Teleconferencing, $\mathrm{K}=$ Interactive Radio Counselling, $\mathrm{L}=$ Gyanvani, $\mathrm{M}=$ Tele Learning Center Activities, $\mathrm{N}=$ Maintenance of database, and $\mathrm{O}=$ Financial \& Administrative Matters

While working at the result of evaluated error (R squared) for admission with respect to other variables it is revealed that the $R$ squared was 0.76 for teleconferencing and 0.75 for maintenance of data base which is significantly higher and indicates training was not up to the mark on these issues.

It is evident to that values of skewness are positive for all variables (Table 8) which indicates that quality of the training was good but improvement is need in the training. Since examination, interactive radio counseling and gyanvani are not correlated with each other the negative result are obtained. The result of kurtosis are also negative for teleconferencing (1.34), interactive radio counseling (0.97), maintenance of database (-1.62), and financial \& administrative matters $(-1.20)$, which indicates that improvement is needed in the training programmes. 
Table 8. Relationship of Examination with other Variables

\begin{tabular}{|c|c|c|c|c|c|c|c|c|c|c|}
\hline \multirow[b]{2}{*}{ 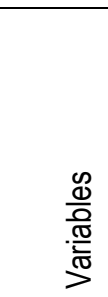 } & \multirow[b]{2}{*}{ 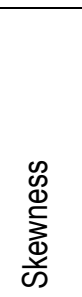 } & \multirow[b]{2}{*}{ 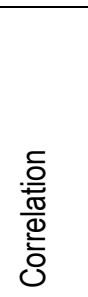 } & \multirow[b]{2}{*}{$\begin{array}{l}\frac{\infty}{\infty} \\
\frac{0}{5} \\
\underline{\underline{T}}\end{array}$} & \multicolumn{7}{|c|}{ Regression } \\
\hline & & & & 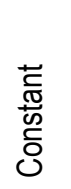 & 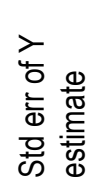 & 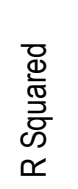 & 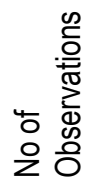 & 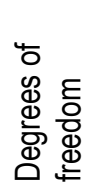 & 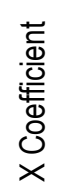 & 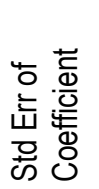 \\
\hline I\&J & 0.17 & 0.87 & $\begin{array}{l}-1.34 \\
\end{array}$ & 0.13 & 1.24 & 0.76 & 5 & 3 & 0.89 & 0.29 \\
\hline$I \& K$ & 0.56 & -0.18 & -0.97 & 1.26 & 2.21 & 0.08 & 5 & 3 & 0.27 & 0.51 \\
\hline$I \& L$ & 1.02 & -0.54 & 0.05 & 2.28 & 1.44 & 0.08 & 5 & 3 & -0.17 & 0.33 \\
\hline$I \& M$ & 0.88 & 0.22 & 1.13 & 1.09 & 1.09 & 0.26 & 5 & 3 & 0.26 & 0.25 \\
\hline$I \& N$ & 0.23 & 0.94 & -1.62 & 0.62 & 0.89 & 0.85 & 5 & 3 & 0.85 & 0.21 \\
\hline $1 \& 0$ & 0.13 & 0.91 & -1.20 & 0.87 & 1.83 & 0.42 & 5 & 3 & 0.62 & 0.42 \\
\hline
\end{tabular}

$\mathrm{H}=$ Admission, I=Examination, ]=Teleconferencing, $\mathrm{K}=$ Interactive Radio Counseling, L=Gyanvani, $\mathrm{M}=$ Tele Learning Center Activities, $\mathrm{N}=$ Maintenance of database, and $\mathrm{O}=$ Financial \& Administrative Matters

Table 9. Relationship of Teleconferencing, Interactive Radio Counselling, Gyanvani, Tale Learning Center Activities, Maintenance of database, and Financial \& Administrative Matters

\begin{tabular}{|c|c|c|c|c|c|c|c|c|c|c|}
\hline \multirow[b]{2}{*}{ 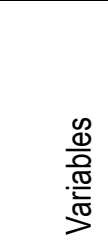 } & \multirow[b]{2}{*}{ 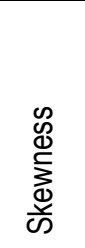 } & \multirow[b]{2}{*}{$\begin{array}{l}\frac{\widetilde{0}}{0} \\
\frac{\pi}{0} \\
\frac{\pi}{0} \\
0\end{array}$} & \multirow[b]{2}{*}{$\begin{array}{l}\frac{\infty}{0} \\
\frac{9}{5} \\
\frac{1}{2}\end{array}$} & \multicolumn{7}{|c|}{ Regression } \\
\hline & & & & 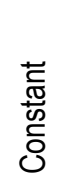 & 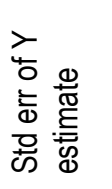 & 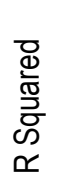 & 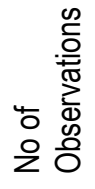 & 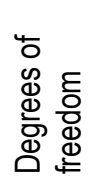 & 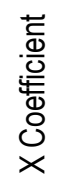 & 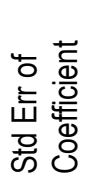 \\
\hline$J \& K$ & 0.34 & 0.29 & -1.52 & 1.26 & 2.21 & 0.08 & 5 & 3 & 0.27 & 0.51 \\
\hline$J \& L$ & 0.64 & -0.28 & -0.95 & 2.28 & 1.44 & 0.08 & 5 & 3 & -0.17 & 0.33 \\
\hline$J \& M$ & 0.43 & 0.51 & -0.12 & 1.09 & 1.09 & 0.26 & 5 & 3 & 0.26 & 0.25 \\
\hline$J \& N$ & -0.05 & 0.92 & -1.79 & 0.62 & 0.89 & 0.85 & 5 & 3 & 0.85 & 0.21 \\
\hline$J \& 0$ & -0.11 & 0.91 & -1.60 & 0.87 & 1.83 & 0.42 & 5 & 3 & 0.62 & 0.42 \\
\hline$K \& L$ & 102 & 0.19 & 0.03 & 155 & 148 & $0 \cap 4$ & 5 & 3 & 013 & 037 \\
\hline$K \& M$ & 0.68 & 0.34 & 0.62 & 1.43 & 1.19 & 0.12 & 5 & 3 & 0.19 & 0.30 \\
\hline K\&N & 0.33 & 0.13 & -1.72 & 2.75 & 2.29 & 0.02 & 5 & 3 & 0.13 & 0.57 \\
\hline K\&O & 0.26 & -0.36 & -1.61 & 3.35 & 2.23 & 0.13 & 5 & 3 & -0.38 & 0.56 \\
\hline 181 & 018 & 067 & 055 & 070 & 001 & 011 & & 2 & 056 & \\
\hline$\frac{L Q 1 v}{1 \& N}$ & 0.71 & -0.58 & -136 & $\frac{0.15}{459}$ & $\frac{0.34}{1.89}$ & 0.43 & $\frac{5}{5}$ & 3 & 0.00 & 072 \\
\hline L\&O & 0.48 & -0.59 & -1.25 & 4.29 & 1.93 & 0.35 & 5 & 3 & -0.94 & 0.74 \\
\hline$M \& N$ & 050 & 023 & $-0, \Delta 0$ & 225 & 225 & 005 & 5 & 3 & 042 & 103 \\
\hline$M \& O$ & 0.19 & 0.07 & -1.25 & 238 & 2.39 & 0.00 & 5 & 3 & 0.13 & 1.09 \\
\hline & & & & & & & & & & \\
\hline $\mathrm{N} \& O$ & -0.11 & 0.84 & -1.75 & -0.03 & 1.28 & 0.17 & 5 & 3 & 0.88 & 0.32 \\
\hline
\end{tabular}

$\mathrm{J}=$ Teleconferencing, $\mathrm{K}=$ Interactive Radio Counseling, $\mathrm{L}=$ Gyanvani, $\mathrm{M}=$ Tele - Learning Center Activities, $\mathrm{N}=$ Maintenance of database, and $\mathrm{O}=$ Financial \& Administrative Matters 
On the other hand the regression analysis of examination with respect to teleconferencing, interactive radio counseling, gyanvani, tele-learning center activities, maintenance of database, and financial \& administrative matters shows that the evaluated error (R squared) was higher for teleconferencing and maintenance of data base.

While analyzing the result of teleconferencing with other variables it is evident to note that the result of skewness were negative for maintenance of data base $(-0.05)$, and financial and administrative matters $(-0.11)$. This indicates that the quality of the training was not up to the mark. Similarly negative correlation was computed for teleconferencing and gyanvani $(-0.28)$, interactive radio counseling and finance and administrative matters $(-0.59)$, gyanvani and financial and administrative matters accounts $(-0.59)$, gyanvani and maintenance of data base $(-0.58)$ reflect that while addressing the training needs of the one topic others were not addressed as a result negative relationship was developed among these variables.

\section{CONCLUSION}

Significant variation has been noticed while looking at the interrelationship among the different variables. It has also been noticed that the issues pertaining to the training of the academics were well addressed and captured the attention of trainees. Nevertheless, there has been wide gap in addressing the certain issues including monitoring of various activities which is very crucial considering the nature of activities to be performed by them. The diversified nature of activities performed by the academics has greatly influenced the result of our analysis to a great extent. However, the academics were more or less satisfied with the quality of training imparted on a number of issues and it has been reflected that training programmes have certainty enhanced their skill. It is also felt that more attention should be paid to address the issues which are more relevant for the day to day requirements of the academics.

\section{REFERENCES}

Bhatnagar, S. (1997). Distance education: A system under stress (pp. 162). New Delhi: Concept Publishing Company.

Dimri, A.K. \& Misra, A.K. (2006). Training programmes for distance education professionals: An analytical assessment. Turkish Online Journal of Distance Education (TOJDE), 7(4), article 5.

Koul, B.N. (1990). Instructional design and course development: A training perspective. In Report on a Round Table on Training Distance Educators. Vancouver: Commonwealth of Learning.

Mullick, S.P. (1997). Academic staff development at national open university: In Santosh Panda (1997) Staff development in higher and distance education (pp.202-203). New Delhi: Viva Aravali Books International.

Murlimanohar, K. (1997). Staff development in distance education: A national perspective. In Santosh Panda (1997) Staff development in higher and distance education (pp. 222223). New Delhi: Viva Aravali Books International.

Murthy, C.R.K. \& Ramanujam, P.R. (1997). Rajiv Gandhi Fellowhip Scheme: Report of the Internal Evaluator. STRIDE Research Report. New Delhi: IGNOU (unpublished).

Panda, S. \& Bala, M. (2004). Online research resources for teachers and trainers. Indian Journal of Open Learning, 13 (1), 119-122. 
Pennell, R. (1996). Managing online learning. In R. Debreceny and A.Ellis (eds) AusWeb 96: Proceedings of the Second Australian World Wide Web Conference. Lismore: Southern Cross University Press.

Ramanujam, P.R. (1995). Reflections on distance education for India (pp.143). New Delhi: Manak Publications Pvt. Ltd.

Yadav, M.S. \& Panda, S.K. (1997). Higher education and professional development. In Santosh Panda (1997) Staff development in higher and distance education (pp.19). New Delhi: Viva Aravali Books International. 